\title{
Investigating the Levels of Soluble Extracellular Domain of HER2 Protein in the Sera of Meningioma Patients
}

\author{
Shabnam ABTAHI ${ }^{1}$, Sareh HAKIMRABET ${ }^{1}$, Mahyar MALEKZADEH ${ }^{1}$, Amir Reza DEGHANIAN ${ }^{2}$, Abbas GHADERI $^{1,3}$ \\ ${ }^{1}$ Shiraz University of Medical Sciences, Shiraz Institute for Cancer Research, Shiraz, Iran \\ ${ }^{2}$ Shiraz University of Medical Sciences, Department of Pathology, Shiraz, Iran \\ ${ }^{3}$ Shiraz University of Medical Sciences, Department of Immunology, Shiraz, Iran
}

\section{ABSTRACT}

AIM: Bearing in mind the association of breast cancer and meningioma, the present study aimed to investigate the levels of the soluble extracellular domain of HER2 protein in meningioma cases and control group. Besides, in the present research, its associations with pathological features and prognostic indicators of meningioma were examined.

MATERIAL and METHODS: A total of 68 meningioma patients along with 20 healthy age-sex matched individuals, as controls, were selected. Levels of HER2 in the sera were measured by a quantitative enzyme-linked immunosorbent assay (ELISA).

RESULTS: The observations showed that Serum HER2 levels in meningioma patients were significantly lower than normal controls. However, outlier quantities were mostly observed in the cases. Furthermore, in meningiomas with higher histological grade (grade II, III), statistically significant elevated serum levels of HER2 were observed compared to patients with low-grade meningiomas (grade I).

CONCLUSION: Serum HER2 levels were a poor biomarker for determination of pathological and prognostic characteristics of meningiomas and coupling serum HER2 levels with immunohistochemistry examination of HER2 in meningioma tissue samples would be helpful in future studies.

KEYWORDS: Cancer biomarker, HER2, Meningioma, Prognosis

ABBREVIATIONS: HER2: Human epidermal growth factor receptor 2, sHER2: soluble extracellular domain of HER2 protein, ELISA: enzyme-linked immunosorbent assay, TAA: tumor-associated antigen, WHO: World Health Organization.

\section{INTRODUCTION}

$\mathrm{M}$ eningiomas are the most frequently diagnosed primary central nervous system tumors in adults, comprising approximately one-third of all cases (26). The incidence of meningioma increases progressively with age and these tumors are more common in women (16). A number of factors have been studied for a possible relationship to the development of meningiomas, including: ionizing radiation, genetic predispositions, hormonal factors, breast cancer, and obesity (18). Considering slightly higher incidence of meningiomas in breast cancer patients and breast cancer in meningioma patients, it can be assumed that both tumors share similar risk factors, such as hormonal risk factors and/or underlying genetic predispositions $(6,26)$.

The HER2 (also known as ERBB2) gene is a proto-oncogene located at 17q12, and encodes a 185-kd transmembrane glycoprotein which belongs to the family of tyrosine kinase growth factor receptors (1). The four members of HER protein family mediate major cellular functions including proliferation, 
differentiation, motility, and survival (4). HER2 gene amplification and/or overexpression have been found in some human cancers, such as gastric, esophageal, endometrial, ovarian, and rarely in lung and bladder cancers (10), but it has been most widely studied in breast carcinomas (9).

In 1993, reports from different studies demonstrated the expression of the HER2 protein in meningiomas $(19,21)$. Considering the association of breast cancer and meningioma, and probable similarities in their risk factors, Chozik et al. hypothesized that altered expression of the HER2 protein was one of the shared pathogenesis pathway, occurring in both breast carcinomas and meningiomas (5). They observed a difference in HER2 expression of typical and atypical meningiomas (5). Further studies demonstrated HER2 gene amplification with Fluorescence In Situ Hybridization (FISH) in meningiomas (13). Besides, reports that showed higher rates of recurrence in HER2-positive meningiomas in comparison to HER2-negative ones $(2,13,23)$, suggested a potential role of HER2 protein expression in the determination of meningioma prognosis. In addition, Wang et al. demonstrated that overexpression of HER2 resulted in meningiomas with increased cell invasion, migration, and proliferation, whereas downregulation of HER2 protein expression inhibited the neoplastic cells' motility and proliferation, which led to an increase in apoptosis and arrest cell cycle at the G0/G1-phase (24). In addition, higher expression of HER2 in higher grades of meningioma (grade II, III) in comparison to low-grade tumors (grade I) has been reported $(13,15)$. On the other hand, there are studies that report no association between HER2 expression and meningioma features (14).

Almostall of the studies on HER2 in meningioma were performed on tumor samples. However, the extracellular domain of HER2 protein can be shed from the surface of neoplastic cells into the circulation and measurement of soluble extracellular domain of HER2 protein in the sera (sHER2) can possibly offer a less invasive method of determining HER2 expression in meningiomas rather than a biopsy. Considering the potential role of HER2 in the determination of meningioma prognosis, the present study aimed to investigate the HER2 serum levels in meningioma cases and to examine its associations with pathological features and prognostic indicators.

\section{MATERIAL and METHODS}

In the present study, 68 meningioma patients were enrolled and underwent surgical treatment at Shahid Chamran Hospital; affiliated with Shiraz University of Medical Sciences. All cases were individuals with newly diagnosed and histologically confirmed meningioma. Histological subtypes were defined based on World Health Organization (WHO) criteria (12), and only age and gender were included in the present study as demographic characteristics. The patients with previous cancer history or recurrent tumors, previous chemotherapeutic or radiotherapeutic treatment, or with synchronous multiple cancers were excluded. Besides, 20 healthy sex-age matched individuals were recruited to establish control group. All participants were informed about the study, and written informed consent was taken. The Declaration of Helsinki (27) was considered and the study was approved by the Ethics Committee of the Shiraz University of Medical Sciences.

In order to perform the test, $5 \mathrm{ml}$ of venous blood was collected from each participant. The samples were centrifuged at $1200 \mathrm{~g}$ for 10 minutes at $4{ }^{\circ} \mathrm{C}$ within 1 hour after collection. The serum was transferred to a fresh tube and stored at $-80^{\circ} \mathrm{C}$ until analysis. Preoperative serum samples were collected from all 68 primary meningioma patients prior to any therapeutic procedures, such as surgery, chemotherapy, or radiotherapy. Level of the soluble extracellular domain of the HER2 protein (sHER2) in the sera was measured by a quantitative enzymelinked immunosorbent assay (ELISA) kit (Sigma-Aldrich; St. Louis, Missouri, United States) according to the protocols described by the manufacturer.

Statistical Package for Social Sciences (SPSS, version 16; SPSS Inc., Chicago, IL, USA) was used for data analysis. Shapiro-Wilk test was employed to determine if values were normally distributed. Variables with normal distribution were presented as the mean \pm standard deviation (SD), otherwise as the median. Frequencies were presented as percentages. Non-parametric tests, including Mann-Whitney U-test and Kruskal-Wallis test, were used to analyze the difference among groups. Pearson correlation was employed to correlate bivariate. $p<0.05$ was considered as statistically significant.

\section{RESULTS}

In the present study, 68 meningioma patients along with 20 healthy age-sex matched individuals, as controls, were involved. The mean age of diagnosis in patients was $53.5 \pm 13.0$ years (range $=24-86$ years), and $69.1 \%(n=47)$ of them were females. Most pathological samples were reported to be grade I meningiomas $(60.3 \% ; n=41)$. Further pathological features of the meningiomas are presented in Table I.

A statistically significant difference between sHER2 levels of cases and control group was observed. Interestingly, the sHER2 levels were significantly lower in the cases compared to control group (Figure 1A; 34.49 vs. $39.65 \mathrm{pg} / \mathrm{ml} ; \mathrm{p}=0.008$ ). Although median of HER2 serum levels were higher in healthy individuals, outlier quantities were mostly observed in the case group (Figure 1A). However, no significant shared characteristics were observed in this group of meningioma. Furthermore, HER2 serum levels were higher in the patients with grade II or III meningioma compared to grade I patients (Figure 1B; 39.18 vs. $33.78 \mathrm{pg} / \mathrm{ml} ; \mathrm{p}=0.016$ ). No other association was observed between serum levels of HER2 and pathological features and histological variants of meningioma.

\section{DISCUSSION}

To our best knowledge, there have been no reports on the levels of serum HER2 in meningioma patients. In the present study, we tried to investigate HER2 serum levels and associate these levels with pathological features and prognostic indicators of meningioma. The observations showed that HER2 serum levels in meningioma patients were significantly lower than the control group. However, outlier quantities were mostly observed in the cases. Furthermore, in meningiomas with higher histological grade (grade II, III), a statistically significant 


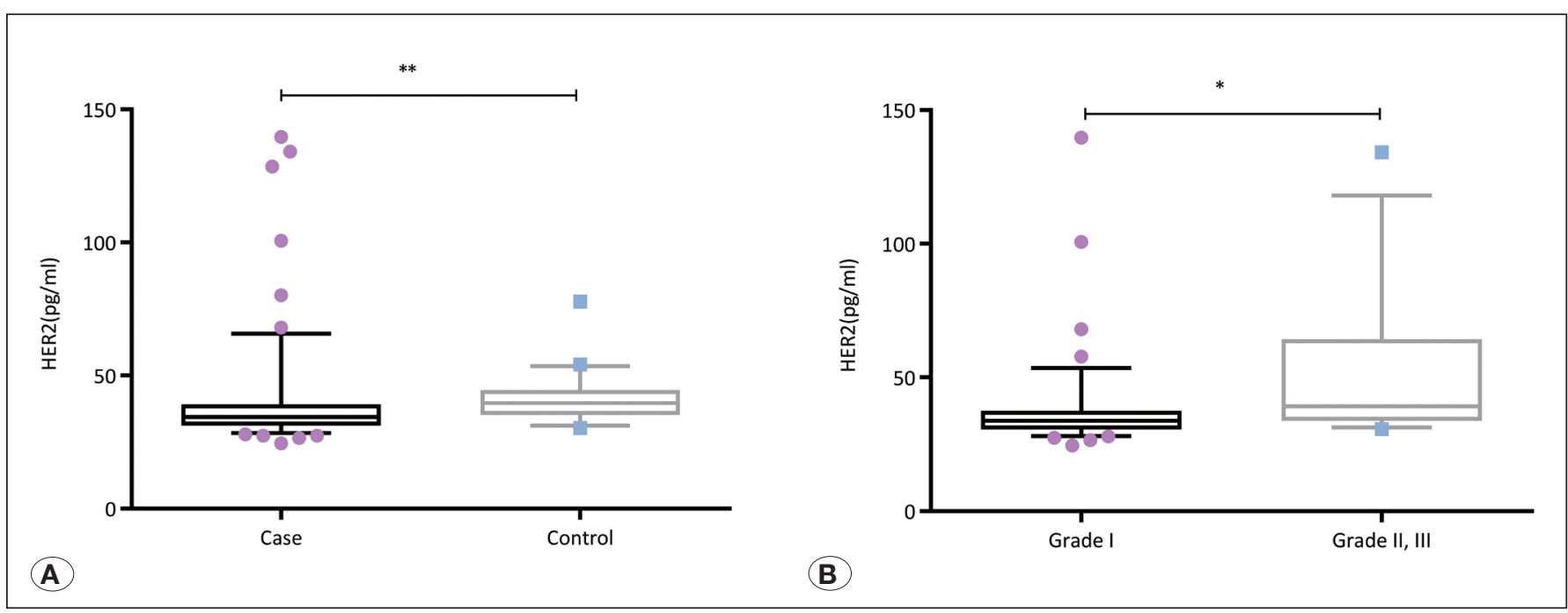

Figure 1: Box-and-whisker diagram of serum HER2 levels; Outliers are plotted as individual points. The middle line of each bar presents the median levels of serum HER2. The bottom and top of the boxes are the first and third quartiles. The ends of the whiskers represent 10-90 percentile; A) serum HER2 levels were significantly lower in than controls (34.49 vs. $39.65 \mathrm{pg} / \mathrm{ml} ; \mathrm{p}=0.008)$; B) HER2 serum levels were higher in the patients with grade II or III meningioma compared to grade I patients (39.18 vs. 33.78 pg/ml; $p=0.016)$.

Table I: Pathological Characteristics of Meningioma Samples and Their Respective Serum HER2 Levels

\begin{tabular}{|c|c|c|c|c|}
\hline Pathological Features & & Valid Percent (n) & HER2 ${ }^{1}(\mathrm{pg} / \mathrm{ml})$ & $p$ value \\
\hline \multirow{3}{*}{ Pathological Grade } & 1 & $77.8(42)$ & 33.78 & \multirow{3}{*}{$0.03^{\star 2}$} \\
\hline & II & $13.0(7)$ & 37.77 & \\
\hline & III & $9.3(5)$ & 39.18 & \\
\hline \multirow{8}{*}{ Histological Variant } & Microcystic & $11.8(2)$ & -4 & \multirow{8}{*}{$0.26^{2}$} \\
\hline & Meningothelial & $5.9(1)$ & -4 & \\
\hline & Fibroblastic & $11.8(2)$ & -4 & \\
\hline & Angiomatous & $17.6(3)$ & -4 & \\
\hline & Secretory & $5.9(1)$ & -4 & \\
\hline & Rhabdoid & $5.9(1)$ & -4 & \\
\hline & Papillary & $23.5(4)$ & -4 & \\
\hline & Anaplastic & $17.6(3)$ & -4 & \\
\hline \multirow{2}{*}{ Brain Invasion } & Yes & $10.3(7)$ & 40.58 & \multirow{2}{*}{$0.11^{3}$} \\
\hline & No & 89.7 (61) & 34.25 & \\
\hline
\end{tabular}

${ }^{1} \mathrm{HER} 2$ serum levels are presented as median; ${ }^{2}$ Kruskal-Wallis test; ${ }^{3} \mathrm{Mann}$-Whitney $U$ test; ${ }^{4}$ Values were not calculated in median because of low number of cases.

elevated serum levels of HER2 was observed in comparison to patients with low-grade meningioma (grade I).

To date, almost all the studies had demonstrated HER2 immunoreactivity in meningiomas; however, the reported range differs considerably (2\% to $100 \%)$ (22). Loussouarn et al. reported that HER2 protein was over-expressed in about $30 \%$ of the meningiomas (13). In this study, we observed that serum levels of HER2 were significantly higher in control group. There are several explanations for the discrepancy we observed. We believe that profile of tissue expression of HER2 in meningioma may not necessarily match with its serum levels. Since in the present research, the expression of
HER2 on the neoplastic cells of meningioma was not studied, the observations in the serum might be the result of HER2 expression in meningiomas expressing poles apart levels of HER2 protein. This also could be the reason that we observed outlier levels of serum HER2 only in the meningioma patients. Furthermore, the patients were pathologically diagnosed with meningioma, which means serum samples were collected at least 2 months after surgery. Therefore, one can expect that the levels of HER2 on the fresh tissue will be different to that of serum samples.

Another explanation for this discrepancy could be the enzymatic digestion of extracellular domain of HER2 shed 
in the blood, which has been previously shown in case of breast cancer (author personal observation). Moreover, tumor cells express many potential immunogenic proteins, called tumor-associated antigen (TAAs), which are also found in normal cells at low levels (8). Durand et al. reported that HER2 expression in meningiomas was higher than in normal meningeal tissue, but was similar in all tumors, regardless of their grade and histological type (7). Higher expression of HER2 in these tumors can activate an immune response against this molecule. The presence of HER2 autoantibodies has been demonstrated in the sera of breast cancer patients $(11,20)$. An additional reason for our observation could be over-expression of HER2 in meningioma patients, which triggers autoantibody production against a HER2 antigen in the serum of meningioma patients, and consequently, inability of the ELISA to detect this antigen.

Up to this point, most studies have been scrutinizing the expression of the HER2 protein in the neoplastic cells of meningioma. Consistent with our observations, Abdelzaher et al. reported a significant direct correlation between HER2 expression in meningiomas and their proliferation index (2). Wang et al. observed that when the gene expression of HER2 was down-regulated, the proliferative and invasive ability of the meningioma cells were decreased, and these cells had higher rates of apoptosis (24). Moreover, consistent with our results, some studies reported the higher expression of HER2 on the surface of higher grade meningiomas, although they stated no statistical significance for this association $(14,15)$. On the other hand, there are studies that report no correlation between HER2 expression and histological grade and prognosis of meningiomas $(17,25)$, and a few studies have even shown decreased HER2 expression in higher grade meningiomas (3).

\section{CONCLUSION}

Levels of serum HER2 are a poor biomarker for determination of pathological and prognostic characteristics of meningiomas. The limitations of this study were the low number of participants and not examining the past medical history of patients more thoroughly. For further clarifying the significance of HER2 serum levels and its association with pathological features, the studies that measure the levels of sHER2 coupled with immunohistochemistry examination of HER2 in meningioma tissue samples would be helpful. Examining the presence of neutralizing autoantibodies against sHER2 in meningiomas with HER2 over-expression would also help further clarify our observations.

\section{ACKNOWLEDGEMENT}

This work was supported by a grant from Shiraz University of Medical Sciences (grant number: 93-01-01-7776 ).

\section{REFERENCES}

1. [No authors listed]: "ERBB2 Erb-b2 Receptor Tyrosine Kinase 2 [Homo Sapiens (human)] - Gene - NCBI." National Center for Biotechnology Information. U.S. National Library of Medicine, n.d. Web. 18 July 2017. <https://www.ncbi.nlm.nih.gov/ gene/2064>.

2. Abdelzaher E, El-Gendi SM, Yehya A, Gowil AG: Recurrence of benign meningiomas: Predictive value of proliferative index, BCL2, p53, hormonal receptors and HER2 expression. $\mathrm{Br} \mathrm{J}$ Neurosurg 25: 707-713, 2011

3. Andersson U, Guo D, Malmer B, Bergenheim AT, Brannstrom $\mathrm{T}$, Hedman $\mathrm{H}$, Henriksson R: Epidermal growth factor receptor family (EGFR, ErbB2-4) in gliomas and meningiomas. Acta Neuropathol 108: 135-142, 2004

4. Blume-Jensen $P$, Hunter $T$ : Oncogenic kinase signalling. Nature 411:355-365, 2001

5. Chozick BS, Benzil DL, Stopa EG, Pezzullo JC, Knuckey NW, Epstein MH, Finkelstein SD, Finch PW: Immunohistochemical evaluation of erbB-2 and p53 protein expression in benign and atypical human meningiomas. J Neurooncol 27: 117-126, 1996

6. Custer BS, Koepsell TD, Mueller BA: The association between breast carcinoma and meningioma in women. Cancer 94: 1626-1635, 2002

7. Durand A, Champier J, Jouvet A, Labrousse F, Honnorat $\mathrm{J}$, Guyotat J, Fevre-Montange M: Expression of c-Myc, neurofibromatosis Type 2, somatostatin receptor 2 and erb-B2 in human meningiomas: Relation to grades or histotypes. Clin Neuropathol 27: 334-345, 2008

8. Finn OJ: Cancer immunology. N Engl J Med 358: 2704-2715, 2008

9. Krishnamurti U, Silverman JF: HER2 in breast cancer: A review and update. Adv Anat Pathol 21: 100-107, 2014

10. Laurendeau I, Ferrer M, Garrido D, D'Haene N, Ciavarelli P, Basso A, Vidaud M, Bieche I, Salmon I, Szijan I: Gene expression profiling of ErbB receptors and ligands in human meningiomas. Cancer Invest 27: 691-698, 2009

11. Lauterlein JJ, Petersen ER, Olsen DA, Ostergaard B, Brandslund I: Quantification of HER2 autoantibodies in the amplification phenomenon of HER2 in breast cancer. Clin Chem Lab Med 49:877-883, 2011

12. Louis DN, Perry A, Reifenberger G, von Deimling A, FigarellaBranger D, Cavenee WK, Ohgaki H, Wiestler OD, Kleihues P, Ellison DW: The 2016 World Health Organization Classification of Tumors of the Central Nervous System: A summary. Acta Neuropathol 131: 803-820, 2016

13. Loussouarn D, Brunon J, Avet-Loiseau H, Campone M, Mosnier JF: Prognostic value of HER2 expression in meningiomas: An immunohistochemical and fluorescence in situ hybridization study. Hum Pathol 37: 415-421, 2006

14. Mahzouni P, Movahedipour M: An immunohistochemical study of HER2 expression in meningioma and its correlation with tumor grade. Pathol Res Pract 208: 221-224, 2012 
15. Ongaratti BR, Silva CB, Trott G, Haag T, Leaes CG, Ferreira NP, Oliveira MC, Pereira-Lima JF: Expression of merlin, NDRG2, ERBB2, and c-MYC in meningiomas: Relationship with tumor grade and recurrence. Braz J Med Biol Res 49: e5125, 2016

16. Ostrom QT, Gittleman H, Fulop J, Liu M, Blanda R, Kromer C, Wolinsky Y, Kruchko C, Barnholtz-Sloan JS: CBTRUS statistical report: Primary brain and central nervous system tumors diagnosed in the United States in 2008-2012. Neuro Oncol 17 Suppl 4: iv1-iv62, 2015

17. Potti A, Panwalkar A, Langness E, Sholes K, Tendulkar K, Chittajalu S, Koch M: Role of HER-2/neu overexpression and clinical features at presentation as predictive factors in meningiomas. Am J Clin Oncol-Canc 27: 452-456, 2004

18. Saraf S, McCarthy BJ, Villano JL: Update on meningiomas. Oncologist 16: 1604-1613, 2011

19. Schlegel J, Ullrich B, Stumm G, Gass P, Harwerth IM, Hynes NE, Kiessling M: Expression of the c-erbB-2-encoded oncoprotein and progesterone receptor in human meningiomas. Acta Neuropathol 86: 473-479, 1993

20. Tabuchi Y, Shimoda M, Kagara N, Naoi Y, Tanei T, Shimomura A, Shimazu K, Kim SJ, Noguchi S: Protective effect of naturally occurring anti-HER2 autoantibodies on breast cancer. Breast Cancer Res Treat 157: 55-63, 2016
21. Torp SH, Helseth E, Unsgaard G, Dalen A: C-erbB-2/HER2 protein in human intracranial tumours. Eur $\mathrm{J}$ Cancer 29A: 1604-1606, 1993

22. Waage IS, Vreim I, Torp SH: C-erbB2/HER2 in human gliomas, medulloblastomas, and meningiomas: A minireview. Int J Surg Pathol 21: 573-582, 2013

23. Wang CL, Mei JH, Wang SS, Xu S, Xu LL, Xiong YF: Expression of HER2/neu in meningiomas: An immunohistochemistry and fluorescence in situ hybridization study. Zhonghua Bing Li Xue Za Zhi 39:156-160, 2010 (In Chinese)

24. Wang W, Tu Y, Wang S, Xu S, Xu L, Xiong Y, Mei J, Wang C: Role of HER-2 activity in the regulation of malignant meningioma cell proliferation and motility. Mol Med Rep 12: 3575-3582, 2015

25. Wickremesekera $A$, Hovens $C M$, Kaye $A H$ : Expression of ErbB-1 and ErbB-2 in meningioma. J Clin Neurosci 17: 11551158,2010

26. Wiemels J, Wrensch M, Claus EB: Epidemiology and etiology of meningioma. J Neurooncol 99: 307-314, 2010

27. World Medical Association: World Medical Association Declaration of Helsinki: Ethical principles for medical research involving human subjects. JAMA 310: 2191-2194, 2013 